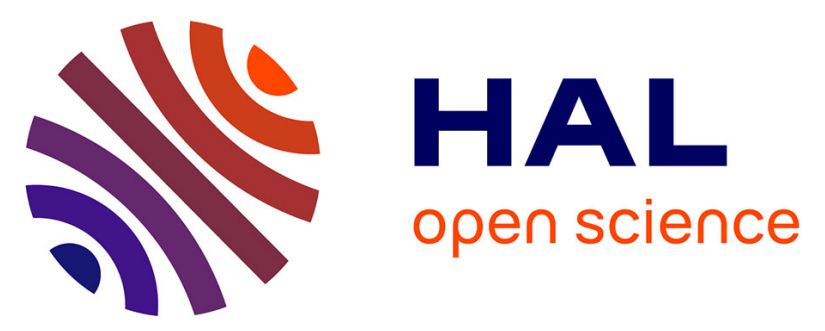

\title{
Spatial analysis of unprotected transients in heterogeneous sodium fast reactors
}

\author{
A. Laureau, Y. Lederer, A. Krakovich, L. Buiron, B. Fontaine
}

\section{To cite this version:}

A. Laureau, Y. Lederer, A. Krakovich, L. Buiron, B. Fontaine. Spatial analysis of unprotected transients in heterogeneous sodium fast reactors. Annals of Nuclear Energy, 2018, 115, pp.554-564. 10.1016/j.anucene.2018.01.029 . cea-02421718

\section{HAL Id: cea-02421718 https://hal-cea.archives-ouvertes.fr/cea-02421718}

Submitted on 20 Dec 2019

HAL is a multi-disciplinary open access archive for the deposit and dissemination of scientific research documents, whether they are published or not. The documents may come from teaching and research institutions in France or abroad, or from public or private research centers.
L'archive ouverte pluridisciplinaire HAL, est destinée au dépôt et à la diffusion de documents scientifiques de niveau recherche, publiés ou non, émanant des établissements d'enseignement et de recherche français ou étrangers, des laboratoires publics ou privés. 


\title{
CEA/IAEC benchmark on neutronic approaches for ULOF and UTOP transient calculations in SFR
}

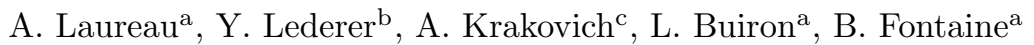 \\ ${ }^{a} C E A, D E N$, DER, Cadarache 13108 Saint-Paul Les Durance Cedex, France \\ ${ }^{b}$ Dept. of Physics, Nuclear Research Center-Negev, Beer-Sheva, Israel \\ ${ }^{c}$ Dept. of Nuclear Physics \&5 Engineering, Soreq Nuclear Research Center, Yavne, Israel
}

\begin{abstract}
The main purpose of this benchmark paper is to study and compare point and spatial neutronic approaches used to calculate ULOF and UTOP transients in sodium cooled fast reactors. A second objective is to compare deterministic and Monte Carlo calculations with two different calculation codes. The first one is based on a deterministic (discrete ordinate $\mathrm{S}_{\mathrm{N}}$ ) approach, using tabulated self-shielded cross sections, where the core reactivity and the power shape distribution are evaluated at each time step of the transient calculation. The second model relies on the Transient Fission Matrix (TFM) approach, condensing the response of a Monte Carlo neutronic code in time dependent Green functions characterizing the local transport in the reactor. This second approach allows a fast estimation of the reactivity and of the flux redistribution in the system during the transient with a precision closed to that of the Monte Carlo code. Both models have been coupled to the thermalhydraulics and applied on an ASTRID representative assembly. This application case is supposed to be sensitive to power redistributions. A second comparison between spatial kinetics and point kinetics calculations has been led to study this point. Finally we obtain a good agreement between spatial and point kinetics on ULOF and UTOP calculations, while some discrepancies are observed between the TFM and the $\mathrm{S}_{\mathrm{N}}$ approaches on the power level stabilization, due to difference on the feedback estimation in both models.
\end{abstract}

Keywords: ASTRID, benchmark, Spatial \& point kinetics, $\mathrm{S}_{\mathrm{N}} \&$ TFM neutronics models, ULOF, UTOP

\section{Introduction}

Simulating reactor behavior during various transient situations requires a coupling between neutronics and other physics such as thermalhydraulics. This coupling 5 acts through the feedback effects linking the temperature (Doppler), the density or the geometry deformation to the neutron behavior in the core. These feedback effects induce an evolution of the total power value and on its distribution in the core. Various approaches exist to model 10 the neutron kinetics depending on the required precision, on the complexity of the studied system and on the computational resources accessible. In order to enhance the precision of the neutronics modeling, many developments concern the consideration of spatial flux redistributions 15 during the transient. In the frame of the study of sodium fast reactors, the capability to predict the spatial decoupling is an important point due to the geometric heterogeneities of core concepts such as the low void concept ASTRID (Ref. [1]). This kind of reactor represented in 30 20 Fig. 1 is composed of both axial and radial heterogeneities. In this frame, a comparison of neutronics models and of calculation tools is performed between the French Alternative Energies and Atomic Energy Commission (CEA) and the Israel Atomic Energy Commission (IAEC) in the 35 25 frame of a benchmark. These studies aim to define the validity domain of point kinetics models for system code applications.

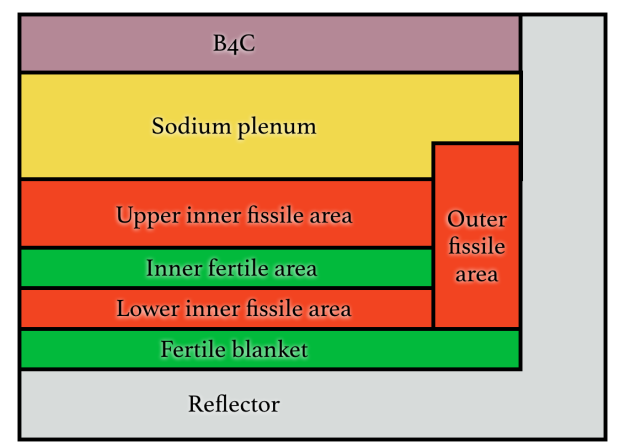

Figure 1: Axial cut of the reference core of ASTRID, with the fuel in red, the fertile matter in green, and the sodium plenum in yellow.

The one dimensional representative assembly of the ASTRID reactor used for this benchmark is described in section 2. Section 3 is devoted to the presentation of the calculation codes used in the study. The two neutronics approaches based on Monte Carlo and deterministic calculations are detailed, together with their spatial and point kinetics applications and their coupling to thermalhydraulics. Finally, the results obtained for ULOF (Unprotected Loss Of Flow) transients with different pump 
time constants and for both beginning of life and end of cycle configurations are presented in section 4. The UTOP (Unprotected Top Of Power accident) transient is

\section{Case presentation}

The application case is a $1 \mathrm{D}$ assembly representative of the ASTRID sodium cooled reactor at beginning of life. Such a reactor can be very sensitive to power redistributions with the two fissile areas separated by a fertile area. A sodium plenum at the top of the geometry amplifies this effect by increasing the neutron leakage from the superior fissile area when the sodium density is reduced. The radial distribution is neglected in this first 1D study, assuming that there is no radial power redistribution.

\subsection{Case geometry}

Figure 2 presents the case geometry. This configuration is very heterogeneous with fertile areas between fissile areas. The sodium plenum is optimized to ensure $a_{75}$ 55 negative sodium void effect (Ref. [2]). If the sodium density decreases, the neutron absorption in the $\mathrm{B}_{4} \mathrm{C}$ increases so that this negative feedback leads to a decrease of the power.

Case B:

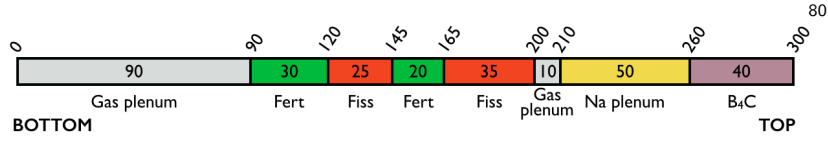

Figure 2: Case geometry

The pin radial description is given in table 1

\begin{tabular}{|l|c|}
\hline Material & Radium $[\mathrm{mm}]$ \\
\hline \hline Central hole (He) & 1.100 \\
\hline Fuel/Fertile pellet & 4.225 \\
\hline Pellet gap (He) & 4.350 \\
\hline Clad & 4.850 \\
\hline Spacing wire & 0.500 \\
\hline
\end{tabular}

Table 1: Pin radial geometry

\subsection{Material characteristics}

The material temperatures and the homogenized isotopic reference compositions of the different areas are given in tab. 2.

The calculations presented here are performed at beginning of life (by default) and at end of cycle with an atomic burnup of 12.2 and 9.92 for the top and bottom fissile areas, and 3.84 and 0.95 middle and bottom fertile areas. In order to compute the feedback coefficients, a material temperature increase of $+300 \mathrm{~K}$ (Doppler effect)

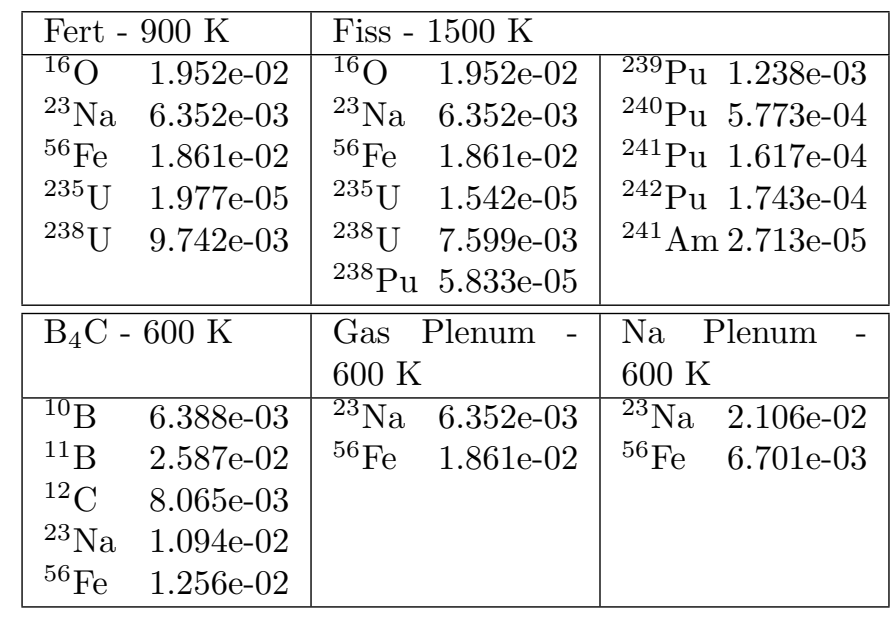

Table 2: Material temperature and composition - $10^{24}$ atoms per $\mathrm{cm}^{3}$

\subsection{Thermalhydraulics characteristics}

The sodium is injected in the assembly at nominal condition at a flow rate of $31 \mathrm{~kg} / \mathrm{s}$, and at $400^{\circ} \mathrm{C}$ corresponding to a density of $0.85514 \mathrm{~g} / \mathrm{cm}^{3}$. The sodium heat capacity is $1265.4 \mathrm{~J} / \mathrm{kg} / \mathrm{K}$ and its expansion factor is $0.000315 \mathrm{~K}^{-1}$. The fuel-clad exchange is $5 \mathrm{~kW} / \mathrm{m}^{2} / \mathrm{K}$, and the clad-coolant exchange is $85 \mathrm{~kW} / \mathrm{m}^{2} / \mathrm{K}$. The fuel thermal conductivity $\mathrm{k}_{\mathrm{th}}$ correlations are extracted from 4 (except for factor $\mathrm{F}_{4}$ from [5]). Using $x$ the fraction of oxygen in the heavy nucleus, $\mathrm{T}$ the fuel temperature in Kelvin, $\beta_{\mathrm{BU}}$ the burnup in at. $\%$ and $\mathrm{p}$ the porosity, the thermal conductivity is calculated using:

$$
\mathrm{k}_{\mathrm{th}}=\mathrm{F}_{1} \mathrm{~F}_{2} \mathrm{~F}_{3} \mathrm{~F}_{4} \mathrm{k}_{\mathrm{th}}^{0}
$$

$$
\text { with : } \begin{aligned}
\mathrm{k}_{\mathrm{th}}^{0}= & \frac{1}{0.06059+0.2754 \sqrt{2-x}+2.011 \cdot 10^{-4} \cdot \mathrm{T}} \\
& +\frac{4.715 \cdot 10^{9}}{\mathrm{~T}^{2}} \exp \left(\frac{-16361}{\mathrm{~T}}\right) \\
\mathrm{F}_{1} & =\omega \arctan \left(\omega^{-1}\right) \\
\mathrm{F}_{2} & =1+\frac{0.019 \beta}{3-0.019 \beta} \frac{1}{1+\mathrm{e}^{-\frac{\mathrm{T}-1200}{100}}} \\
\mathrm{~F}_{3} & =1-\frac{0.2}{1+\mathrm{e}^{\frac{\mathrm{T}-900}{80}}} \\
\mathrm{~F}_{4} & =\frac{1-\mathrm{p}}{1+2 \mathrm{p}} \\
\text { where } \omega & =1.09 \beta^{-3.265}+0.0643 \beta^{-0.5} \mathrm{~T}^{0.5}
\end{aligned}
$$

The fuel thermal capacity $\mathrm{C}_{\mathrm{p}}$ (in $\mathrm{J} / \mathrm{kg} / \mathrm{K}$ ) correlation extracted from [5] is calculated using:

$\mathrm{C}_{\mathrm{p}}=\mathrm{C}_{0}+2 \mathrm{C}_{1} \tau-3 \mathrm{C}_{2} \tau^{2}+4 . * \mathrm{C}_{3} \tau^{3}-5 . \mathrm{C}_{4} \tau^{3}-\mathrm{C}_{-2} \tau^{-2}$ 
With:

$$
\begin{aligned}
\tau & =\mathrm{T} / 1000, \text { where } \mathrm{T} \text { in Kelvins } \\
C_{0} & =193.238 \\
C_{1} & =162.864 \\
C_{2} & =104.001 \\
C_{3} & =29.205 \\
C_{4} & =1.950 \\
C_{-2} & =2.644
\end{aligned}
$$

Theses correlations are represented in Figs. 3 and 4 at the beginning of the irradiation. Note the important variation of this parameter in the fuel temperature range requiring to consider their evolution in the transient calculations.

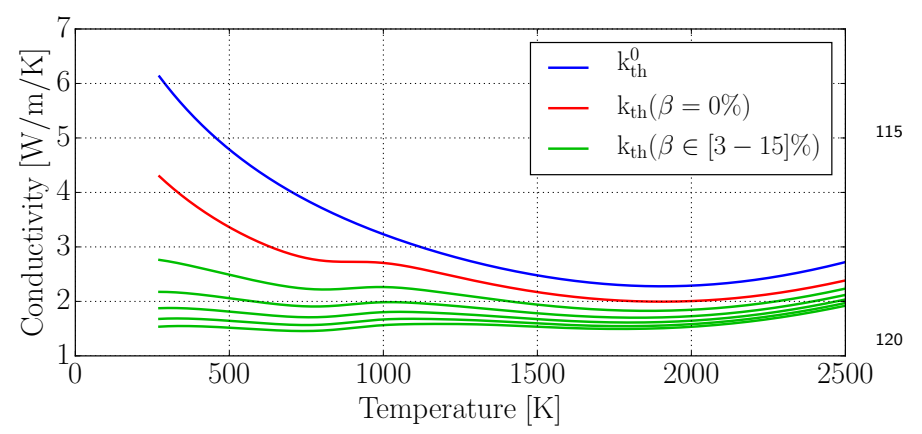

Figure 3: Fuel thermal conductivity as a function of the fuel temperature

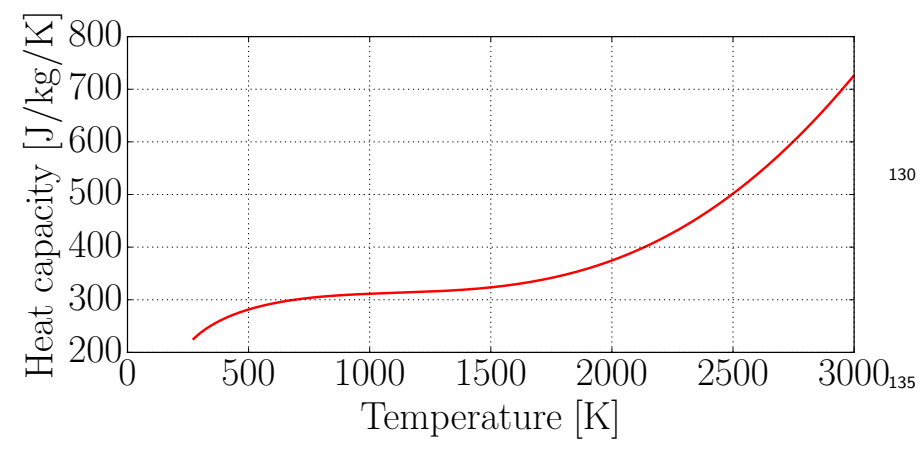

Figure 4: Fuel heat capacity as a function of the fuel temperature

\section{Calculation code presentation}

Two calculation codes are used in this study. Both are composed of a neutronics - thermalhydraulics coupling. This study aims to compare the neutronic modeling used: ${ }^{145}$ the deterministic $\mathrm{S}_{\mathrm{N}}$ (section 3.1.2) and the Monte Carlo based TFM (section 3.2.2 models. Both are capable to perform spatial kinetics and point kinetics calculations.

\subsection{Modeling used at IAEC}

\subsubsection{Thermalhydraulics model}

The thermalhydraulic part of the code describes the generation and heat removal from an average fuel pin inside the core. The heat source, associated to the fission rate, is provided using the axial power density calculated by the neutronic part of the code throughout the transient. The assembly thermalhydraulics is modeled as a 1D flow with an imposed flow rate at the assembly inlet. At each time step, the local velocity is calculated using the imposed flow rate boundary condition and the sodium density variation. The heat removal from the cooling sodium channel is described by axial convection, and the heat removal from the fuel pin to the coolant by radial diffusion along the fuel pin and clad, assuming that the axial diffusion is negligible. The time dependent flow rate is an external parameter assumed to be known and thus not calculated by the code.

As mentioned, fuel and coolant temperatures provided by the thermalhydraulic part of the code are used to calculate either the space dependent cross-sections if one is interested in solving the spatial neutron transport equation, or to calculate the reactivity if one is interested to describe the neutron evolution under the point kinetics (PK) assumption.

\subsubsection{Neutronics model}

The deterministic calculations are based on the traditional two level lattice/core scheme. First, the self-shielded cross sections are computed at CEA by the ECCO (Ref [6]) cell code, using the fundamental mode assumption for each kind of materials of the 1D core description. For fissile material, a buckling search algorithm is used to obtain the critical flux for the cross sections collapsing to a 33 energy group mesh. For the subcritical materials such as fertile or structural parts of the 1D subassembly, the process is based on source calculations using the spectrum coming from previous fissile calculations. The isotopic cross sections are computed once for all at the different temperatures and considered as constant over time in the following calculations. Their dependency with the temperature is assumed to be linear with the sodium density variation and logarithmic with the temperature variation. The fundamental mode hypothesis used here does not seem to be the most realistic assumption regarding the 1D model of the core, but these calculation schemes inherited from PHENIX and SUPERPHENIX studies are the only ones available in the ECCO package.

The neutronic part of the code then solves the time dependent transport equations, written for a one dimensional slab geometry (Ref. 7]): 


$$
\begin{aligned}
& \frac{1}{v} \frac{\partial \phi(x, E, \boldsymbol{\Omega}, t)}{\partial t}=\mathscr{L}(x, E, \boldsymbol{\Omega}, t) \phi(x, E, \boldsymbol{\Omega}, t) \\
& +\frac{1}{4 \pi} \sum_{f} \chi_{f}(E) \lambda_{f} C_{f}(x, t)+S(x, E, \boldsymbol{\Omega}, t), \\
& \frac{\chi_{f}}{4 \pi} \frac{\partial C_{f}(x, t)}{\partial t}=-\frac{\chi_{f}}{4 \pi} \lambda_{f} C_{f}(x, t)+ \\
& \mathscr{F}_{f}^{d}(x, E, \boldsymbol{\Omega}, t) \phi(x, E, \boldsymbol{\Omega}, t), \quad f=1, \ldots, F,
\end{aligned}
$$

where $F$ is the number of delayed neutron precursor families. The symbol $\mathscr{L}(x, E, \boldsymbol{\Omega}, t)$ denotes the time-dependent transport operator including stream- ${ }^{195}$ ing, absorption, scattering and prompt fission, and $\mathscr{F}_{f}^{d}(x, E, \boldsymbol{\Omega}, t) \phi(x, E, \boldsymbol{\Omega}, t)$ is the delayed neutron precursor group production rate.

The code solves the steady state equations for the neutron flux and its adjoint version for the adjoint flux by the $\mathrm{S}_{\mathrm{N}}$ method of discretization for the neutron angle $\boldsymbol{\Omega}$ (Ref. 8]) with $\mathrm{N}=16$ and with 33 energy groups corresponding to the self-shielded cross sections prepared as described above. The boundary conditions are a flux leakage on the axial boundaries, and a volumetric leakage modeling the radial leakages.

The time evolution of the neutron flux is described following the assumption of the Predictor-Corrector version 200 of the Improved Quasi-Static (IQS) method (Ref. [8, 9]): the time-dependent neutron flux is split into the product of two functions called amplitude and shape:

$$
\phi(x, E, \boldsymbol{\Omega}, t)=P(t) \psi(x, E, \boldsymbol{\Omega}, t)
$$

The amplitude function $P(t)$ depends only on time and provides the bulk information about the power change, while the shape function $\psi(x, E, \boldsymbol{\Omega}, t)$ depends on all the variables describing the (time-dependent) power profile deformation. The Predictor-Corrector version of the IQS method evaluates a predicted angular flux using a macro time scale for discretization, typically the same as the one chosen for the thermalhydraulic part of the code. The method assumes that the error resulting from the macro time discretization is related to the amplitude function - The predicted flux is used to estimate the shape function and to the calculated effective parameters for the point kinetics equations. Then one solves the point kinetics equations on a micro time scale, for a corrected estimated amplitude function. Once new amplitude is known, ${ }_{220}$ cursor concentrations. During the transient, local cross sections are given using a pre-calculated polynomial dependence on the coolant density and fuel temperature, provided by thermalhydraulic part of the code. For the pose of comparison, the point kinetics version of the solution is trivially achieved by assuming that the shape function remains constant throughout the transient. For this case, the code calculates the local reactivity coefficients at the beginning of the transient, which drives the point kinetics equations and then calculates at each time step the reactivity using the local values for the coolant density and fuel temperature provided by the thermalhydraulic part of the code.

\subsection{Modeling used at CEA and single physics comparison}

\subsubsection{Thermalhydraulics model}

The simplified thermalhydraulics calculations are performed with a 1D motion using the fluid mechanics calculation code OpenFOAM (Ref. 10). Despite reference tools for thermalhydraulics applied to fuel bundle exist, we choose a fast calculation tool developed in previous work (Ref. [1]). The velocity field is represented in Fig. 5

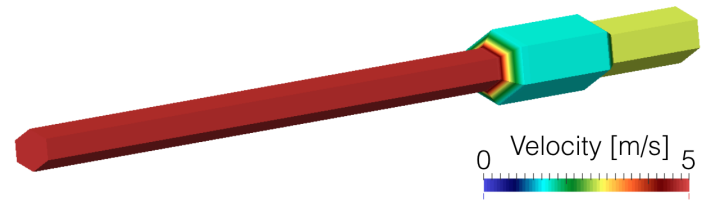

Figure 5: Velocity field

The section of the geometry simulated in OpenFOAM represents the average sodium axial section that changes in the different regions. Since the fluid dilatation is not considered in this thermalhydraulics computation, the fluid velocity only depends on the sodium fraction with a constant flow rate. Then, if the sodium section is smaller, the fluid velocity is larger as we can see in Fig. 5 with the smaller sodium section in the pin area (gas, fertile and fissile areas).

Both the sodium and the fuel average temperatures are calculated during the transient. The heat exchange coefficient between the two media is computed on the fly at each axial position and time step. The pin temperature radial distribution is reconstructed together with the average sodium-fuel heat exchange. The pin temperature field is presented in Fig. 6 for each code, together with a reference solution (green) based on a large number of volumes (10000 bins in the fuel and 1000 bins in the steel clad). A sensitivity study on the number of discretizations (see Fig 7) leads to a discretization of 16 bins in the fuel and 4 in the steel clad to limit the error to $0.3 \mathrm{~K}$ which is well negligible compared to the temperature variation in the pin.

\subsubsection{Neutronics model}

The neutronics approach is based on a perturbative version of the Transient Fission Matrix (TFM) approach. The TFM approach described in Ref.[11, 12, 13] is based on the utilization of fission matrices and average time transport matrices to compute neutron kinetics. The matrices are estimated using a Monte Carlo calculation once per core configuration, and prior to the transient calculation. Different matrices $\underline{\underline{G}}$, depending on the neutron spectrum 


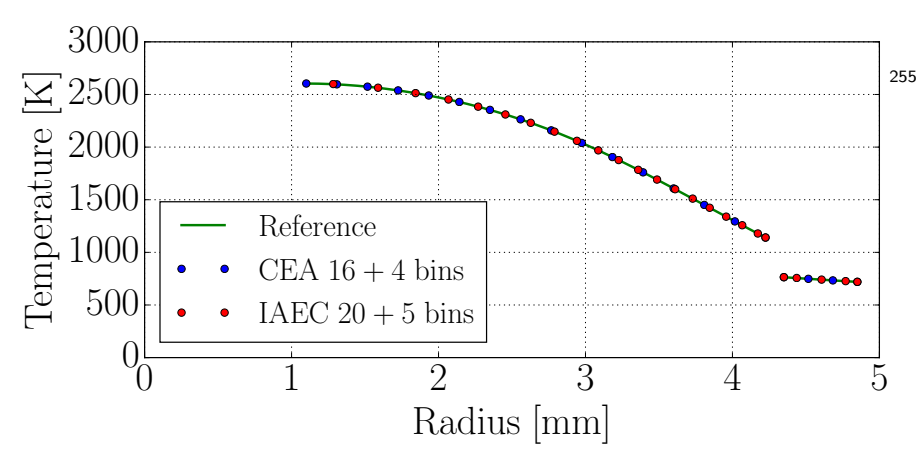

Figure 6: Radial temperature distribution associated to an imposed pin-power of $50 \mathrm{~kW} / \mathrm{m}$ and a sodium temperature of $700 \mathrm{~K}$, with 16 bins in the fuel and 4 in the steel for the CEA calculation, and respectively 20 and 5 for IAEC

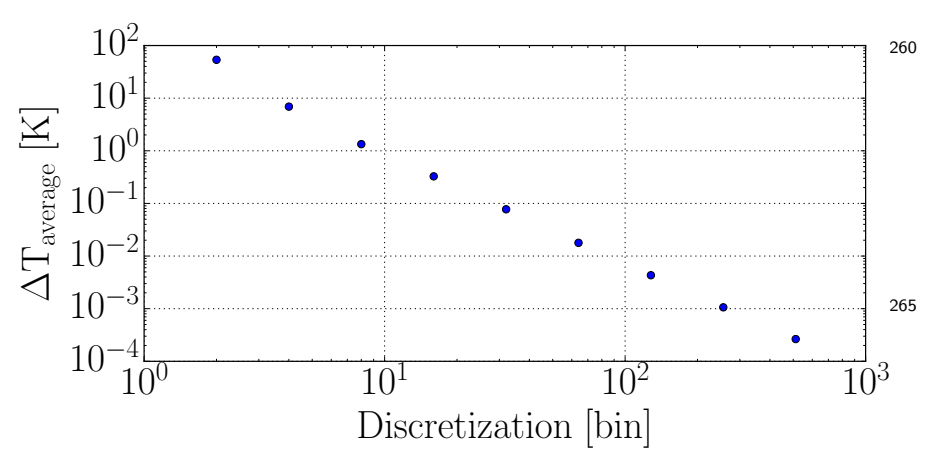

Figure 7: Error on the average fuel temperature as a function of the number of discretizations

(prompt $\chi_{\mathrm{p}}$ or delayed $\chi_{\mathrm{d}}$ ) and the neutron multiplicity (prompt $\nu_{\mathrm{p}}$ or delayed $\nu_{\mathrm{d}}$ ), are estimated during the same calculation. Those matrices contain the neutron propagation spatial and temporal behavior of the system, so that no more Monte Carlo calculation is required during the ${ }_{270}$ transient calculation thanks to an interpolation of the matrices performed on the fly to follow the system evolution. Such an interpolation model is thus implemented in the TFM approach.

Due to the large influence of the crossed volumes during the neutron transport between its creation position and its fission position in an heterogeneous reactor, a correlated sampling (CS) technics (Ref. 14]) has been applied to study sodium cooled reactors such as ASTRID. The CS technics provides a perturbed estimation of the fission ma- ${ }_{280}$ trices using a neutron weight perturbation that depends on the effect of a crossed section modification due to a sodium density or fuel temperature (Doppler) modification. Considering $\underline{\underline{G}}_{\chi_{\mathrm{x}} \nu_{\mathrm{x}}}$, any of the matrices of the TFM approach, and applying a CS weighting for a sodium density variation ${ }_{285}$ of $-1 \%$ or a local temperature of $+300 \mathrm{~K}$, the effect of a local perturbation in the subvolume k on $\underline{\underline{G}}_{\chi_{\mathrm{x}} \nu_{\mathrm{x}}}$ is written $\underline{\underline{G}}_{\chi_{\mathrm{x}} \nu_{\mathrm{x}}}^{\text {den k }}$ for the density effect and $\underline{\underline{G}}_{\chi_{\mathrm{x}} \nu_{\mathrm{x}}}^{\text {dop k }}$ for the Doppler effect. These matrices are called perturbed matrices. $\mathrm{Fi}_{290}$ nally, using $T(\mathrm{k})$ and $\Delta \rho_{\text {sodium }}(\mathrm{k})$ the fuel temperature ${ }^{290}$ and the sodium density variations in volume $\mathrm{k}$, the matrix $\underline{\underline{G}}_{\chi_{\mathrm{x}} \nu_{\mathrm{x}}}$ is interpolated using a linear interpolation for the density effect and a logarithmic interpolation for the Doppler effect as:

$$
\begin{aligned}
\underline{\underline{G}}_{\chi_{\mathrm{x}} \nu_{\mathrm{x}}}\left(\Delta \rho_{\text {sodium }}(\mathrm{k}), \mathrm{T}(\mathrm{k})\right) & =\underline{\underline{G}}_{\chi_{\mathrm{x}} \nu_{\mathrm{x}}} \\
& -\sum_{\mathrm{k}} \underline{\widetilde{G}}_{\chi_{\mathrm{x}} \nu_{\mathrm{x}}}^{\mathrm{den} \mathrm{k}} \cdot \Delta \rho_{\text {sodium }}(\mathrm{k}) \\
& +\sum_{\mathrm{k}} \underline{\widetilde{G}}_{\chi_{\mathrm{x}} \nu_{\mathrm{x}}}^{\text {dop k }} \frac{\log \left(T(\mathrm{k}) / T_{\text {ref }}(\mathrm{k})\right)}{\log \left(\left(T_{\mathrm{ref}}(\mathrm{k})+300\right) / T_{\mathrm{ref}}(\mathrm{k})\right)}
\end{aligned}
$$

During transient calculations, the matrices of the TFM approach are then updated using this interpolation model in order to estimate the fission neutron redistribution and the reactivity variation calculated with the temporal integration presented in Ref. [12. The final kinetics equations solved for the prompt neutrons $\left(\boldsymbol{N}_{\mathrm{p}}(t)\right)$ and precursors of delayed neutrons of each family f $\left(\sum_{\mathrm{f}} \lambda_{\mathrm{f}} \boldsymbol{P}_{\mathrm{f}}(t)\right)$ are the following:

$$
\begin{aligned}
\frac{\mathrm{d} \boldsymbol{N}_{\mathrm{p}}}{\mathrm{d} t}=\underline{\underline{G}}_{\chi_{\mathrm{p}} \nu_{\mathrm{p}}} \frac{1}{l_{\mathrm{eff}}} \boldsymbol{N}_{\mathrm{p}}+\underline{\underline{G}}_{\chi_{\mathrm{d}} \nu_{\mathrm{p}}} \sum_{\mathrm{f}} \lambda_{\mathrm{f}} \boldsymbol{P}_{\mathrm{f}}-\frac{1}{l_{\mathrm{eff}}} \boldsymbol{N}_{\mathrm{p}} \\
\frac{\mathrm{d} \boldsymbol{P}_{\mathrm{f}}}{\mathrm{d} t}=\frac{\beta_{\mathrm{f}}}{\beta_{0}}\left(\underline{\underline{G}}_{\chi_{\mathrm{p}} \nu_{\mathrm{d}}} \frac{1}{l_{\mathrm{eff}}} \boldsymbol{N}_{\mathrm{p}}+\underline{\underline{G}}_{\chi_{\mathrm{d}} \nu_{\mathrm{d}}} \sum_{\mathrm{f}} \lambda_{\mathrm{f}} \boldsymbol{P}_{\mathrm{f}}\right)-\lambda_{\mathrm{f}} \boldsymbol{P}_{\mathrm{f}}
\end{aligned}
$$

where $l_{\text {eff }}$ is the effective prompt lifetime calculated with the time matrix, and $\beta_{\mathrm{f}} / \beta_{0}$ the fraction of delayed neutrons of family $f$. The matrix-vector multiplications correspond to the source terms, each source corresponding to a specific matrix. These matrices are updated at each time step using the interpolation model with the perturbed matrices and the sodium density and fuel temperature modifications.

As mentioned, the TFM approach requires to compute these specific matrices once, prior to the transient calculation. All the matrices are calculated with a modified version of the Serpent 2.1.21 code (Ref. [15]). One billion of neutrons are simulated and the system boundary is a neutron leakage.

Note that the reactor radial dimension has been adjusted to reach criticality, the value obtained with Serpent is $k_{\mathrm{eff}}=0.99980 \pm 0.00002$.

Concerning the point kinetics resolution, the power shape is constant and provided by the spatial kinetic calculation at nominal power. Instead of interpolating the fission matrices during the transient, the reactivity weight of each perturbed matrix is performed prior to the point kinetics calculation to produce the spatial feedback coefficient distribution in the reactor used during the transient. The distributions obtained for the ASTRID representative assembly considered here are presented in Fig. 8 and 9 


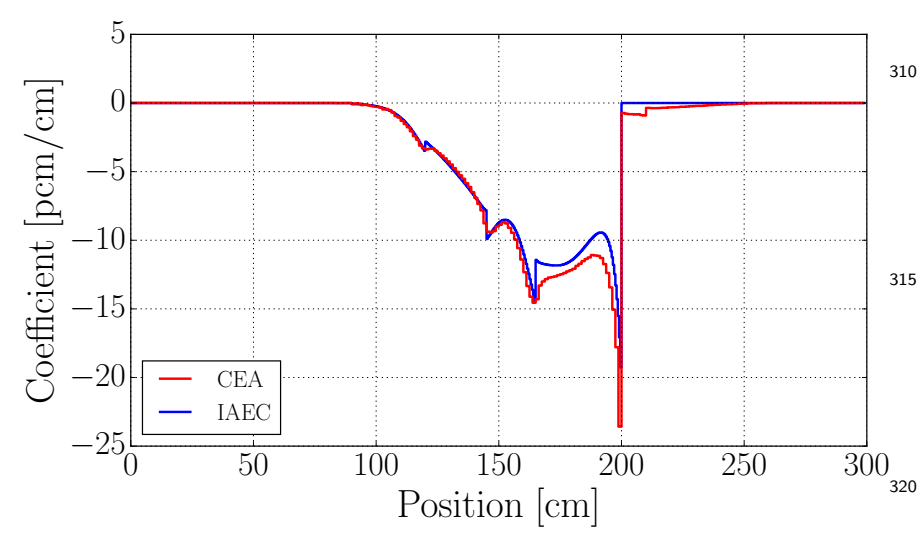

Figure 8: Axial Doppler feedback coefficient

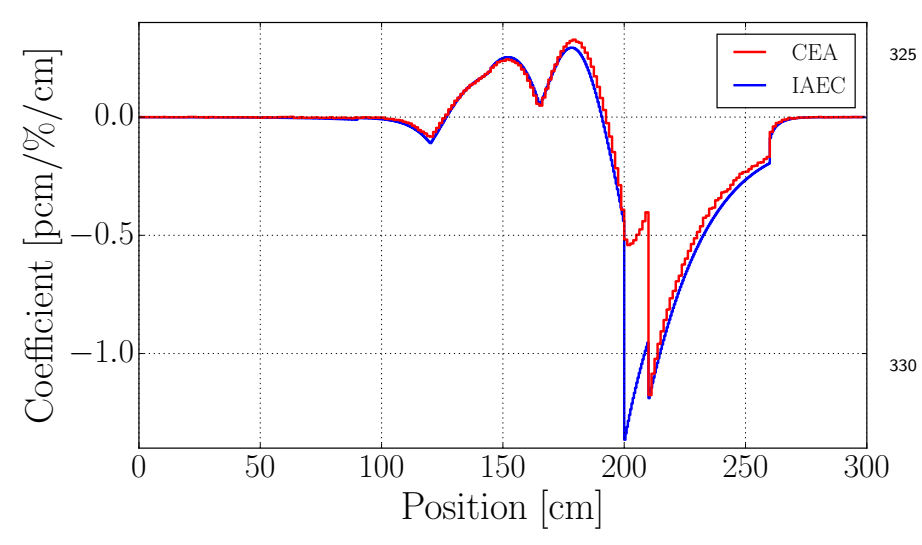

Figure 9: Axial density feedback coefficient

We can see a good global agreement between the CEA-

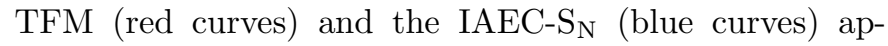
proaches. A difference can be noticed in the gas plenum between 200 and $210 \mathrm{~cm}$ on the density feedback. This difference is due to the deterministic modeling approximation: this area is thin and the neutron spectrum is very different between the neutrons going from the fuel to the sodium plenum and the neutrons that are reflected from sodium plenum. This effect is visible on the global feedback effect presented in Tab. 3, where the reference value corresponds to a direct Monte Carlo calculation. The point kinetics values correspond to the sum of the local contributions of Fig. 8 and 9. The last column of Tab. 3 corresponds to a local sodium density decrease of $-10 \%$ in the upper gas plenum.

\begin{tabular}{|l|c|c|c|}
\hline Case & $\begin{array}{c}\text { Density } \\
-1 \%\end{array}$ & $\begin{array}{c}\text { Doppler } \\
+300 \mathrm{~K}\end{array}$ & $\begin{array}{c}-10 \% \text { density } \\
\text { in } 200-210 \mathrm{~cm}\end{array}$ \\
\hline$\Delta \rho_{\text {Ref }}$ & $-21.2 \pm 1.6$ & $-171.8 \pm 1.6$ & $-51.2 \pm 2.4$ \\
\hline$\Delta \rho_{\text {CEA }}$ & -20.1 & -182 & -49.1 \\
\hline$\Delta \rho_{\text {IAEC }}$ & -30.7 & -159 & -111 \\
\hline
\end{tabular}

Table 3: Global reactivity variation in pcm

Note that the value of PK-CEA corresponds to a sum ${ }_{345}$ of local contributions. There is a bias since the crossed ef- fects between these local perturbations are not taken into account. If we generate the perturbed matrix associated to a global perturbation on the whole reactor, the reactivity variations are respectively of $-20.2 \mathrm{pcm}$ and -171 pcm for the density and the Doppler effects. These values are consistent with the direct Monte Carlo calculation (see 5 Tab. 3). The difference between CEA (Monte Carlo with local correlated sampling approach) and IAEC ( $\mathrm{S}_{\mathrm{N}}$ perturbations using the direct and adjoint flux) comes from the neutron spectrum variation and anisotropy at the interface between the different areas. We can observe a larger effect on the density feedback in the gas plenum in Fig. 9 . also quantified in the right column of Tab. 3. It may be explained either by the difference in the self-shielded cross sections between the reflected neutrons and the leaking ones due to the spectrum difference and the large steel density variation; or by the neutron leakage model used during the cross section self-shielding process.

\section{ULOF transient calculation}

\subsection{Introduction}

The Unprotected Loss Of Flow accident consists in a sodium flow rate reduction due to a pump failure. We consider for the benchmark an imposed exponential reduction of the flow rate down to the minimal flow rate due to the natural convection of $7 \%$ of the nominal value, with a decrease rate of $T_{1 / 2}=20 \mathrm{~s}$ (see Fig. 10 .

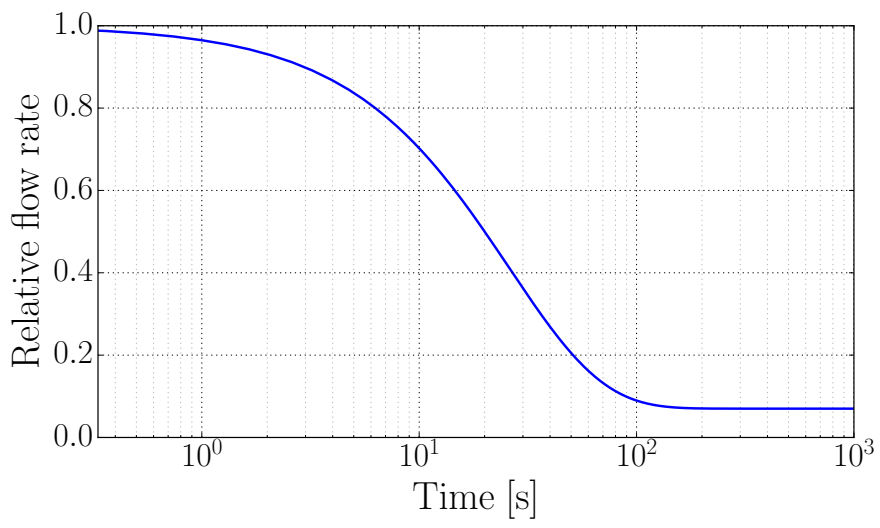

Figure 10: Flow rate evolution imposed during the ULOF transient

As detailed in section 3, two calculation codes from CEA and IAEC are used in this benchmark and both of them can use spatial kinetics (SK) and point kinetics (PK). They will be referred to as CEA-SK, CEA-PK, IAEC-SK and IAEC-PK. Just a sentence to remind that the CEA neutronics module uses the TFM approach based on a Monte Carlo pre-calculation, and the IAEC neutronics module uses a $\mathrm{S}_{\mathrm{N}}$ deterministic approach. One additional calculation called CEA-PK $\mathrm{IAEC}_{\mathrm{C}}$ has been performed, using the IAEC PK parameters in the CEA numerical tool to check that the results obtained are the same with equivalent neutron kinetic inputs. 


\subsection{Transient analysis}

This section presents the results of the ULOF calculation using the CEA-SK and CEA-PK calculation codes. The SK approach provides the power redistribution, and the PK approach the local feedbacks. Figure 11 shows the assembly at the beginning (top) and at the end (bottom) of the transient calculated with CEA-SK. Due to the

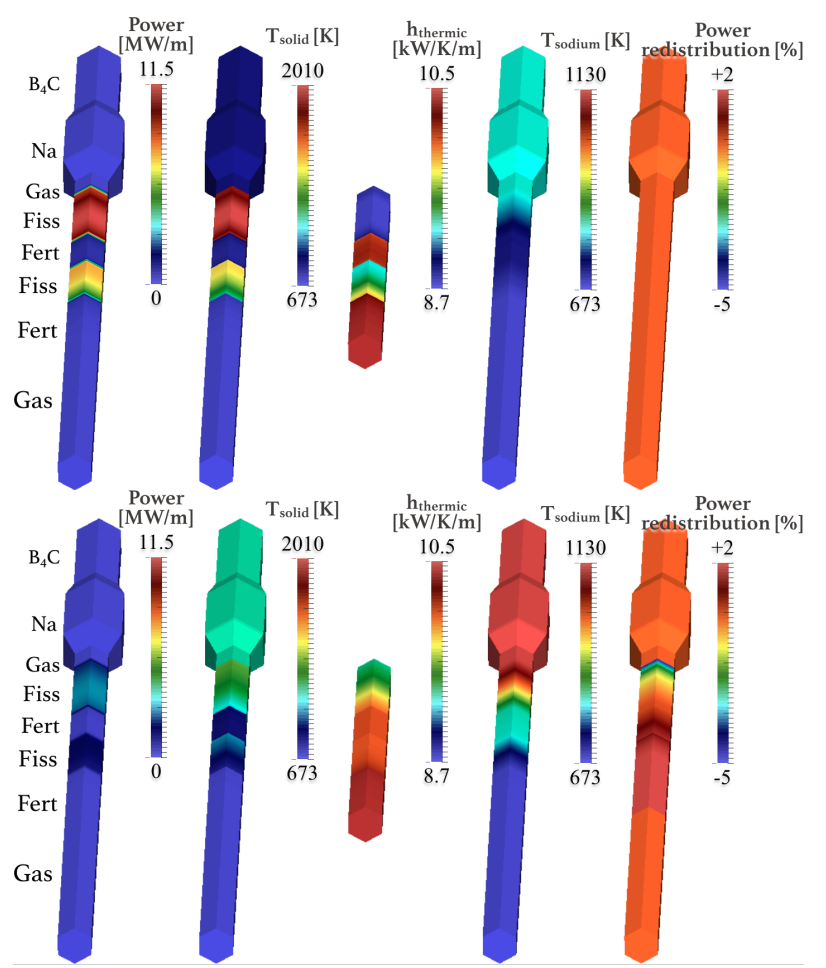

Figure 11: Overview of the reactor at the beginning (top) and at the end (bottom) of the transient with a representation from left to right of: the power, the solid (fuel and structures) temperature, the heat transfer coefficient, the sodium temperature and the power redistribution

loss of flow, the sodium temperature is increasing during the transient. Due to the negative feedback effect, the power level decreases. According to this power decrease, the fuel temperature also decreases to adjust the temperature difference between the fuel and the sodium. Finally, the power level stabilizes once the positive feedback of the fuel compensates the negative feedback of the sodium. The final power level here is around $20 \%$ of the nominal power. This value results of this balance effect between the fuel ${ }_{390}$ and the sodium, so that it is sensitive to the feedback coefficients. The power redistribution in the assembly is around $-5 \%$ at the fuel - sodium plenum interface and $+2 \%$ at the bottom. Due to the sodium dilatation, the neutron leakage from the fuel to the $\mathrm{B}_{4} \mathrm{C}$ increases, result- ${ }_{395}$ ing in a strong local reduction of the power shape. This effect results in a redistribution of the power in the lower fissile area.

Figure 12 presents the evolution of the axial power in the assembly (ordinate) as a function of time (abscissa) ${ }_{400}$ during the transient (left), together with the power redistribution in the assembly (right) calculated with CEA-SK.
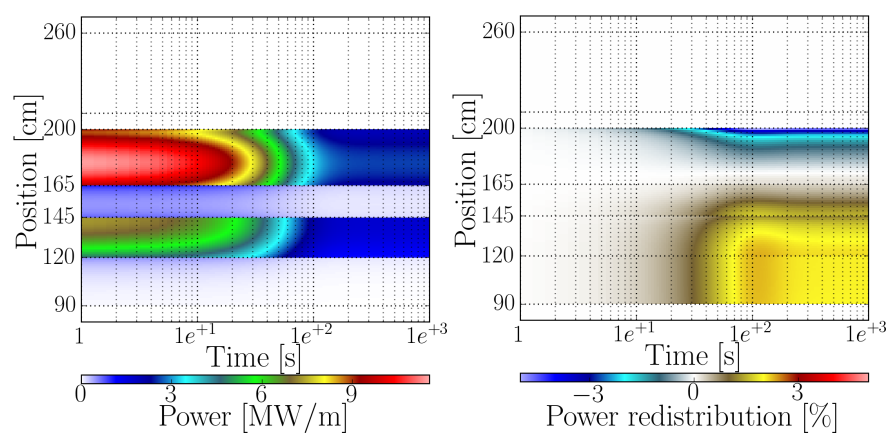

Figure 12: Power evolution map

The redistribution is the normalized power variation compared to the initial value. Note that the horizontal dashed lines separate the different areas of the geometry (fuel, fertile matter, gas plenum...). The initial and final values correspond to the results presented in Fig. 11 . During the transient the power level evolves, and we can see that the power redistribution is maximum at around $100 \mathrm{~s}$. As expected, the power level in the fertile area is low because of the small content of fissile matter.

Figures 13 and 14 present the evolution calculated with CEA-PK of respectively the fuel temperature and the sodium temperature (left), together with their impact on the reactivity (right) due to the sodium dilatation and the Doppler effect.
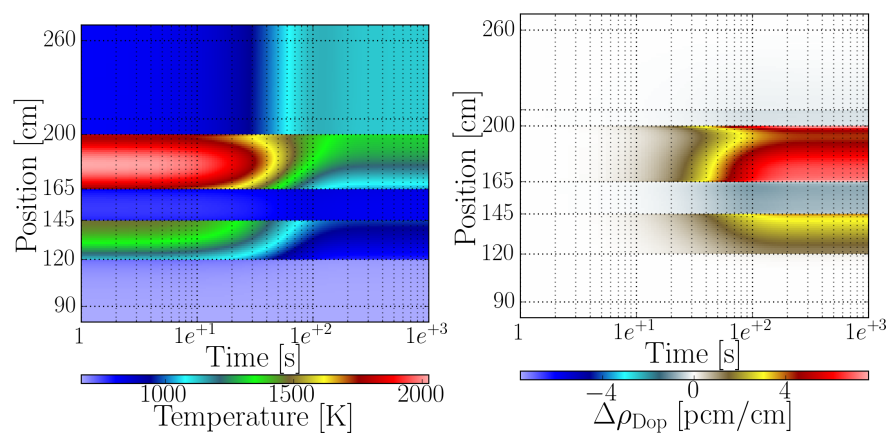

Figure 13: Fuel temperature evolution map (left) and impact on the reactivity (right)

The areas with the higher power production directly correspond to the positions where the fuel temperature is higher (in red at the beginning of the transient), and where the sodium temperature increases. Note that the sodium temperature stays below the boiling temperature $(1155 \mathrm{~K})$.

We can see (Fig. 13 and 14 - right) the effect on the reactivity of the temperature variations. The power reduction is due to the strong negative sodium density feedback effects in the sodium plenum. The contribution of the fuel area is slightly positive, but thanks to the progressive increase of temperature, this component is smaller than the negative one. The fuel temperature reduction induces a 

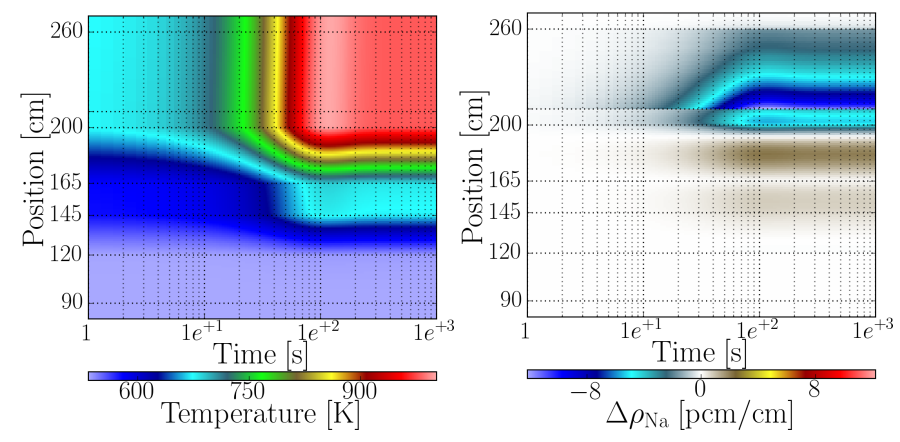

Figure 14: Sodium temperature evolution map (left) and impact on the reactivity (right)

positive reactivity increase with a large component in the middle and the bottom of the upper fissile area. We can note a skin effect at the interface between the fuel and the gas plenum. Due to the sodium temperature increase, even if the power level is smaller, the middle fertile area temperature slightly increases, inducing a small positive reactivity component.

\subsection{Influence of the neutronics model}

Figures 15, 16 and 17 present the temperature, reactivity and power evolutions during the transient using the different codes and SK/PK models.

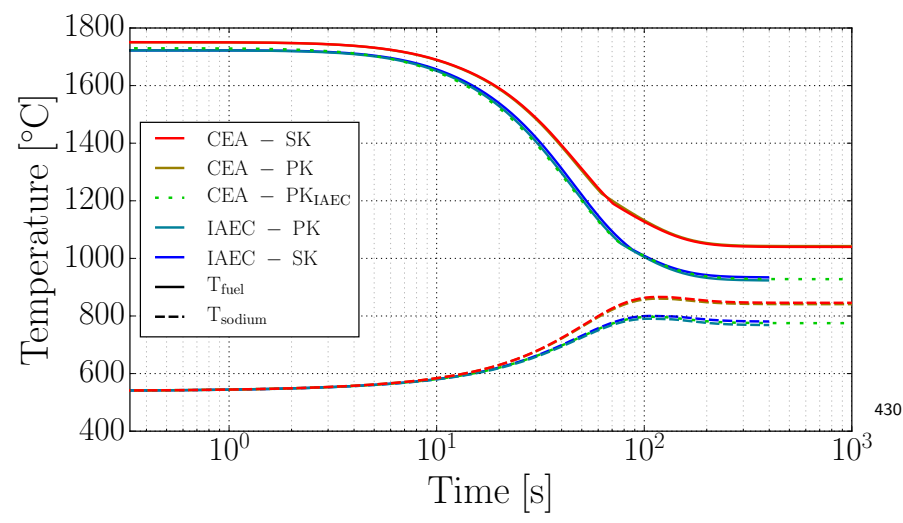

Figure 15: Evolution of the fuel and sodium maximum temperatures - ULOF

Due to the feedback effect, the power level decreases during the transient, resulting in a reduction of the temperature difference between the sodium and the fuel. The reactivity reaches a minimum value during the transient, around $-70 \mathrm{pcm}$, and slowly comes back to $0 \mathrm{pcm}$ with $_{440}$ a time constant associated to the precursor equilibration. All the calculation codes and neutronic models provide a similar behavior during the transient.

Prior to the precise comparison of the different neutronics models, one has to notice (Fig. 15, 16, 17) that the ${ }_{445}$ ULOF CEA-PK IAEC (green dashed line) calculation with the IAEC point kinetics parameters shows a very good

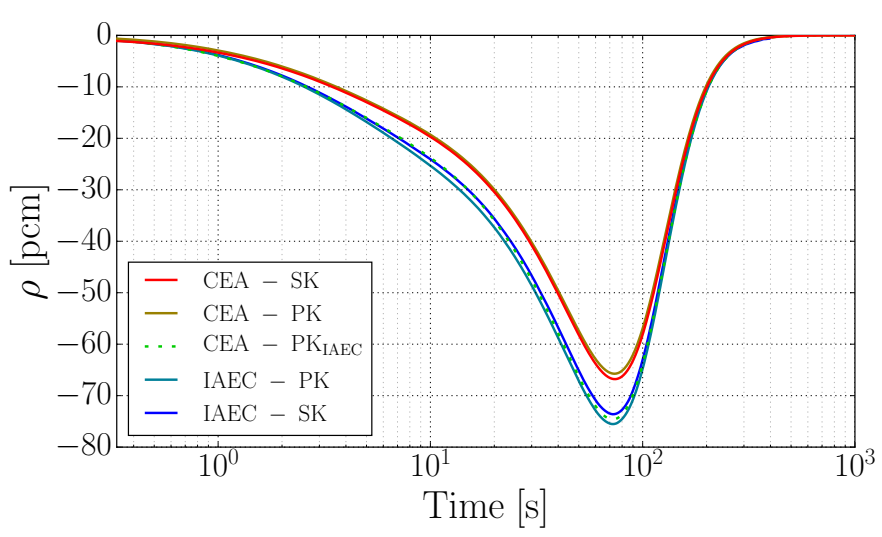

Figure 16: Reactivity evolution - ULOF

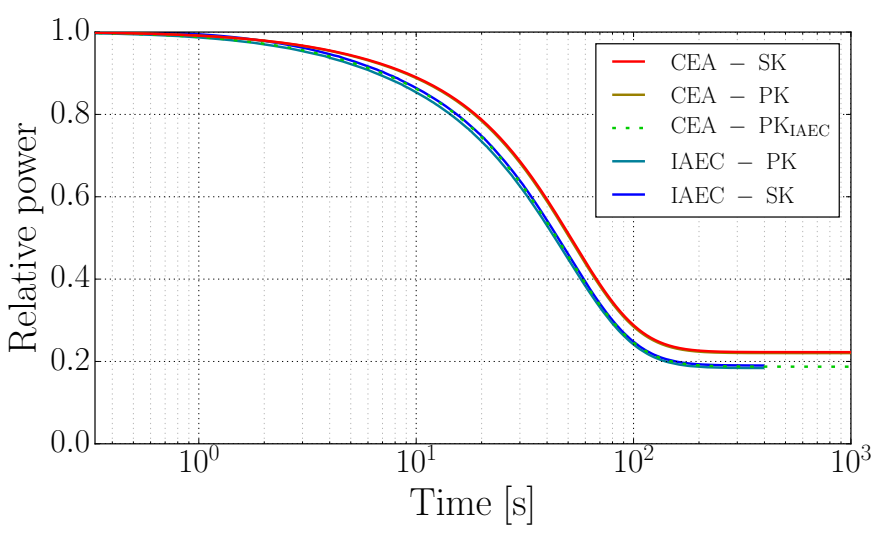

Figure 17: Relative power evolution - ULOF

that the differences in the thermalhydraulics modeling do not impact the results and the differences described in the next section are due to the neutronics models.

\subsubsection{Spatial kinetics versus point kinetics models}

The PK and SK modelings show a very good agreement respectively between $\mathrm{CEA}-\mathrm{PK}$ and $\mathrm{CEA}-\mathrm{SK}$, and between IAEC-PK and IAEC-SK results. The power stabilization is the same and the temperature variations are superimposed. The difference on the reactivity maximum variation is limited to $3 \mathrm{pcm}$. Using point kinetics calculations is correct in such a slow transient, even for a heterogeneous geometry as the case considered here.

\subsection{2. $T F M$ versus $\mathrm{S}_{\mathrm{N}}$ approaches}

The larger difference is obtained between the TFM (CEA-PK/SK) and the $\mathrm{S}_{\mathrm{N}}$ (IAEC-PK/SK) neutronics models. The reactivity difference during the transient increases to a maximum value of $10 \mathrm{pcm}$. Due to the difference on the feedback effects, the final temperature equilibration is not the same and the discrepancy is around $100 \mathrm{~K}$. The final power level results of this coupling between the sodium density decrease with a negative reactivity contribution and the fuel temperature with a positive 
contribution. Finally, the propagation of the feedback difference between the two approaches implies a power level difference of $5 \%$ ( $18 \%$ for IAEC and $23 \%$ for CEA).

\subsection{Influence of the flow rate reduction time constant}

In order to confirm these conclusions with a smaller transient time constant, the ULOF calculation has been performed with a time constant of $T_{1 / 2}=5 \mathrm{~s}$ instead of

$20 \mathrm{~s}$. The results on the temperature, the reactivity and the power ratio are represented in Figs. 18, 19 and 20.

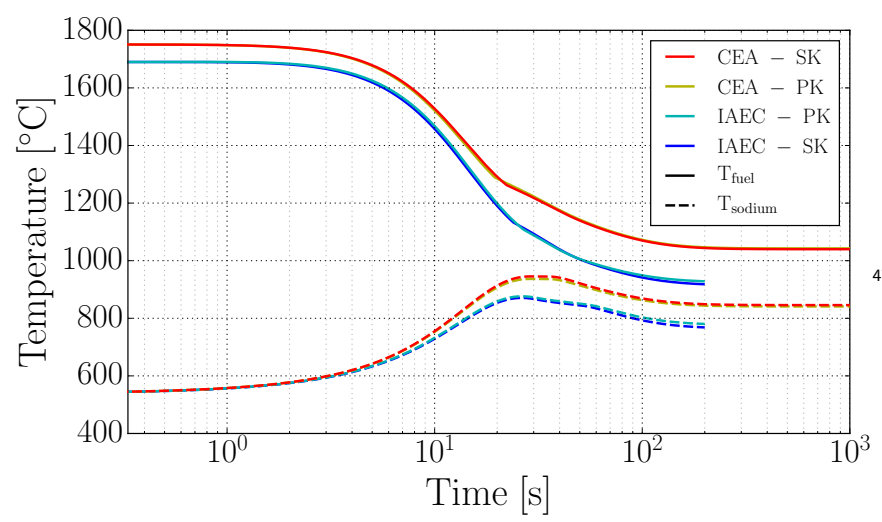

Figure 18: Evolution of the fuel and sodium maximum temperatures - fast ULOF

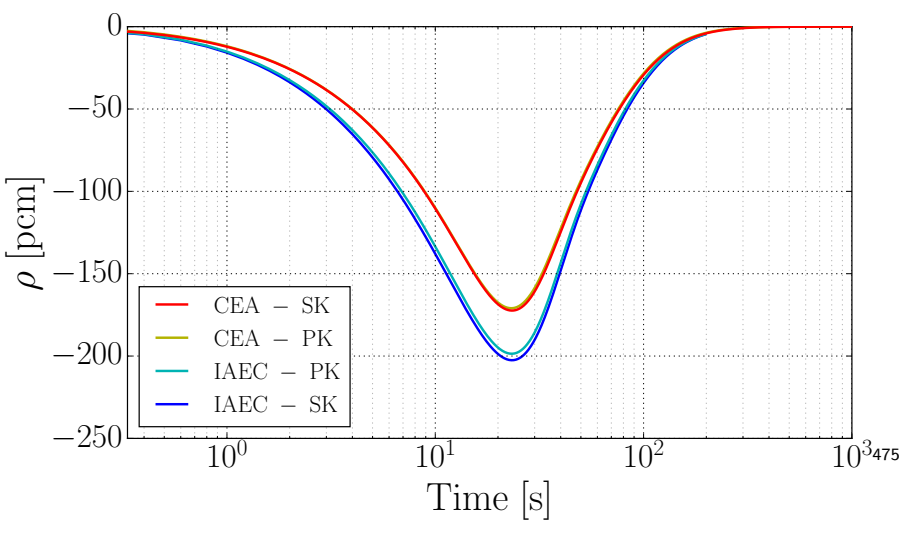

Figure 19: Reactivity evolution - fast ULOF

Similar results are obtained. Due to the smaller time480 constant, the minimum reactivity is smaller, around $180 \mathrm{pcm}$ at $22 \mathrm{~s}$ versus $-70 \mathrm{pcm}$ at $70 \mathrm{~s}$ in the previous changed, the power stabilises at the same final power. The main difference between the results are linked to the neu-485 tronics approach (deterministic of stochastic). Finally we can see that on such a fast ULOF simulation, no important

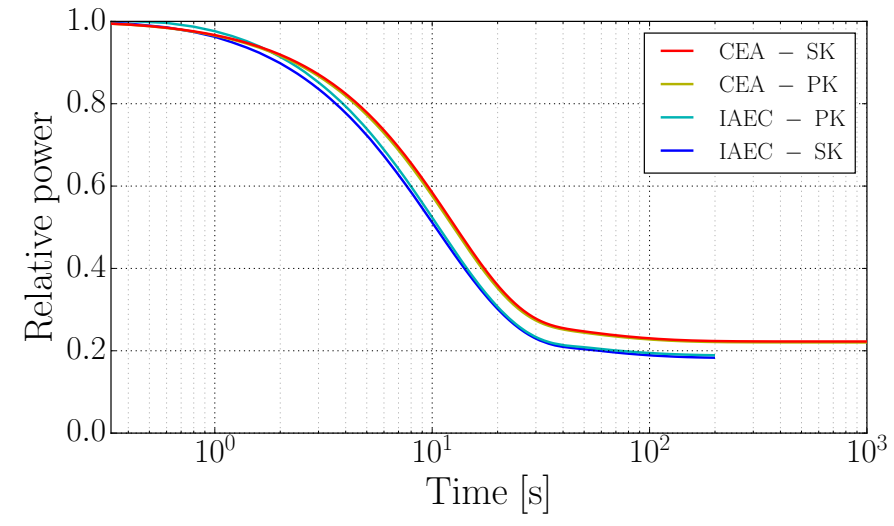

Figure 20: Relative power evolution - fast ULOF

point kinetics local feedback coefficients extracted from a new Serpent calculation are presented in Figs. 21 and 22. Note that the distinction between the fissile and fertile areas is smoother due to the production of plutonium in the fertile areas during the cycle.

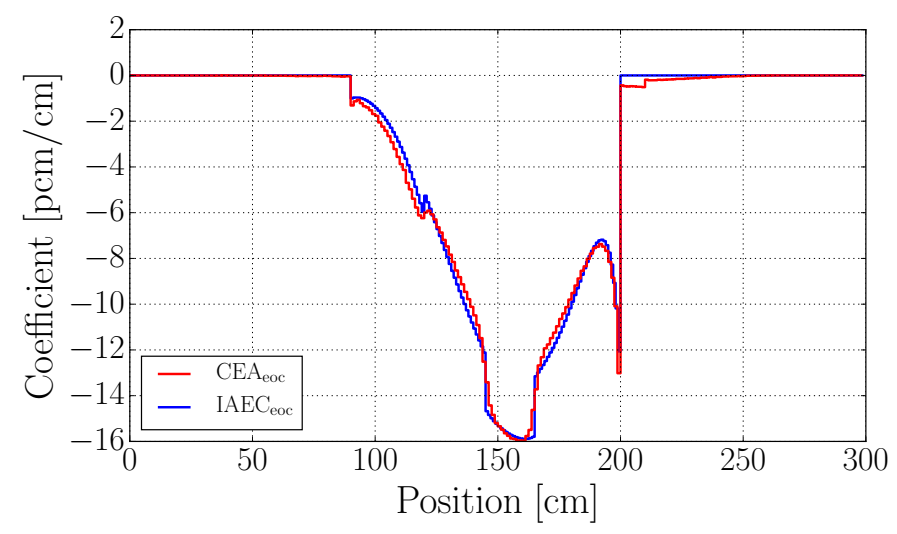

Figure 21: Axial Doppler feedback coefficient at end of cycle

The evolutions of the reactor temperature, reactivity and power ratio during the ULOF are represented in Figs. 23,24 and 25.

We can see that the final power level is higher than at beginning of life due to the difference in the feedback effects. A global reduction of the sodium density of $1 \%$ induces a reactivity variation of $-2.9 \mathrm{pcm}$ versus $-20.1 \mathrm{pcm}$ at beginning of life. Indeed the contribution of the sodium plenum in the density feedback distribution (Fig. 22) is decreased together with the importance of the sodium reflected neutrons since a larger part of the fissions occurs in the fertile areas. The difference between IAEC and CEA is slightly increased compared to the beginning of life results due to the feedback difference.

\subsection{Influence of the burnup}

The ULOF transient has also been studied for the end of cycle (EOC) configuration presented in section 2.2. The 


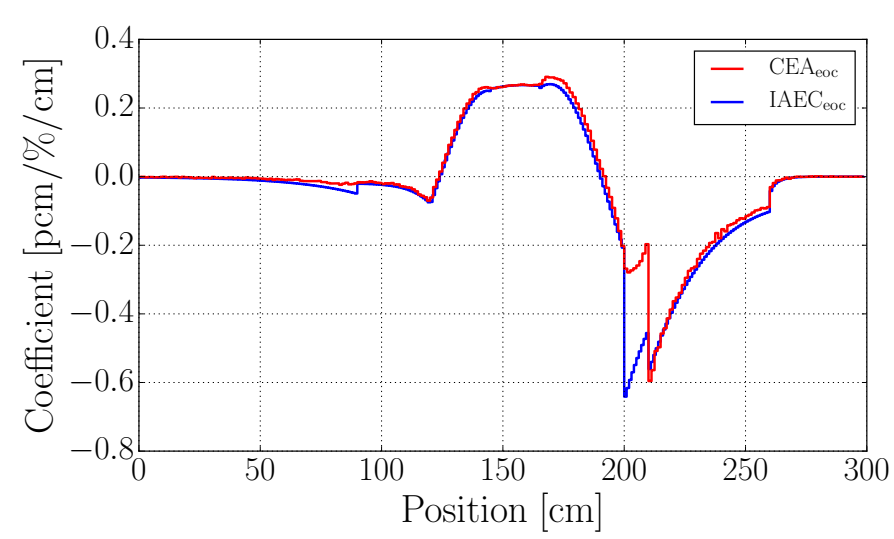

Figure 22: Axial density feedback coefficient at end of cycle

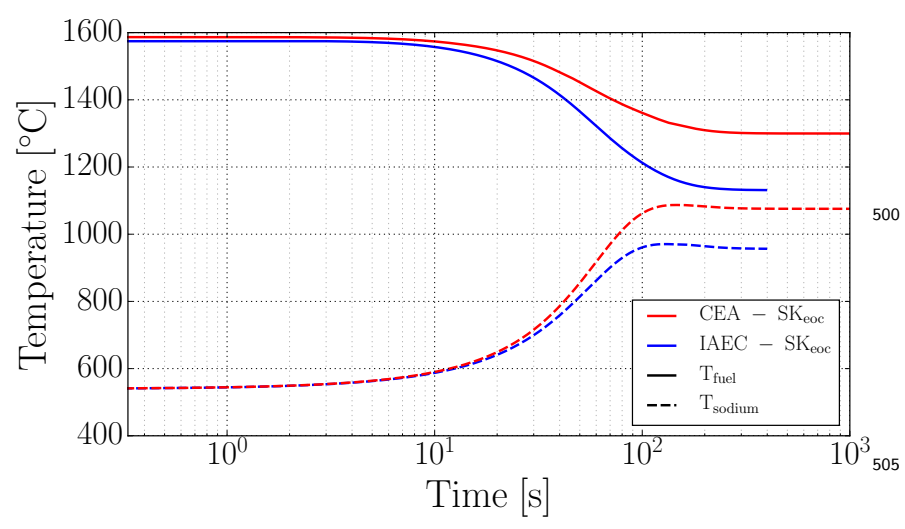

Figure 23: Evolution of the fuel and sodium maximum temperatures - EOC ULOF

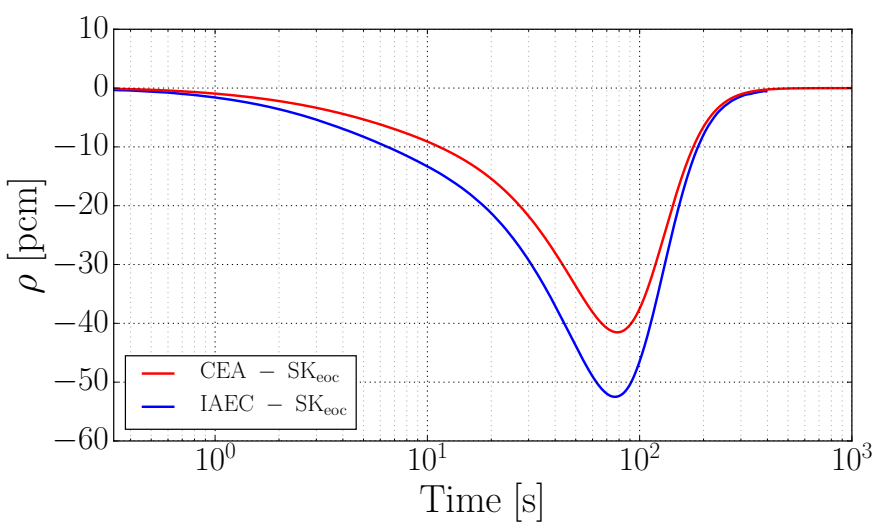

Figure 24: Reactivity evolution - EOC ULOF

\section{UTOP transient calculation}

\subsection{Introduction}

The Unprotected Top Of Power accident consists in a reactivity weight insertion. We considered for this benchmark an imposed linear reactivity variation of $100 \mathrm{pcm}$ between $10 \mathrm{~s}$ and $100 \mathrm{~s}$. The calculation performed with the IAEC calculation tool models the reactivity variation

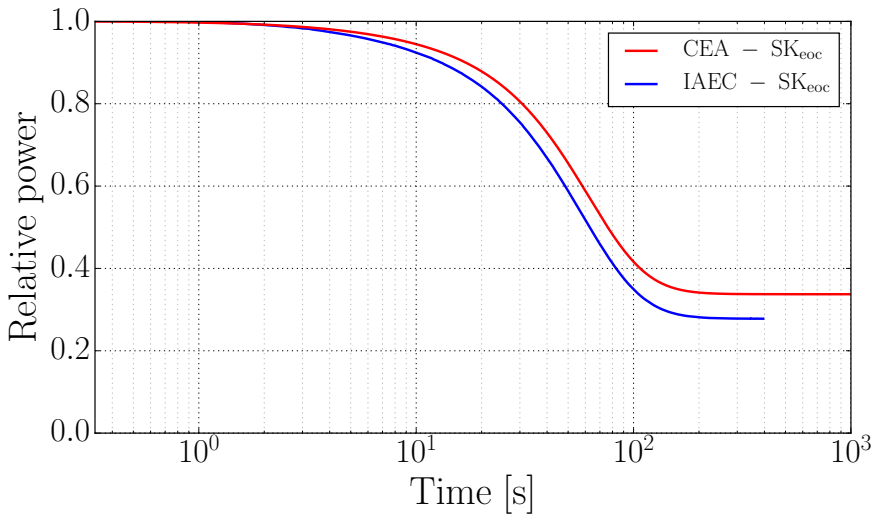

Figure 25: Relative power evolution - EOC ULOF

between this density and the reactivity being tabulated prior to the transient calculation. Concerning the CEA calculation tool, the reactivity variation is modeled as a fission matrix renormalization that directly acts on the Eigenvectors $\left(k_{\text {eff }}\right)$ of the matrices.

\subsection{Transient analysis}

During the first 10 seconds, the power, the fuel temperature and the sodium temperature are stable in the core as respectively presented on the left column of Figs. 26, 27 and 28 .
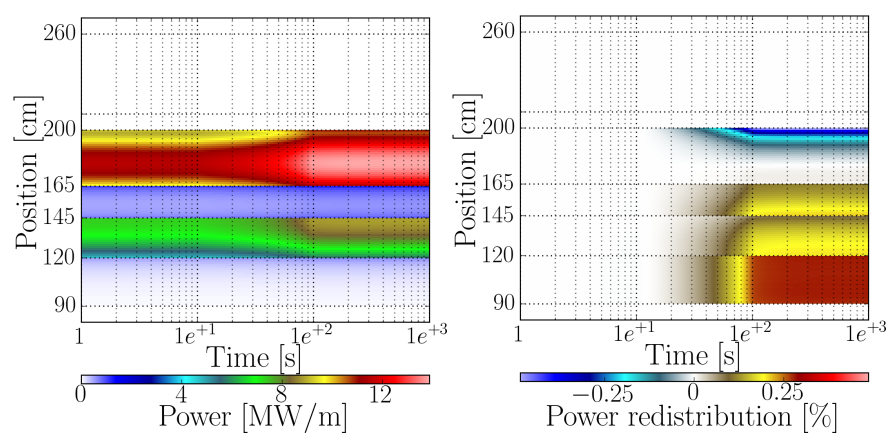

Figure 26: Power evolution map
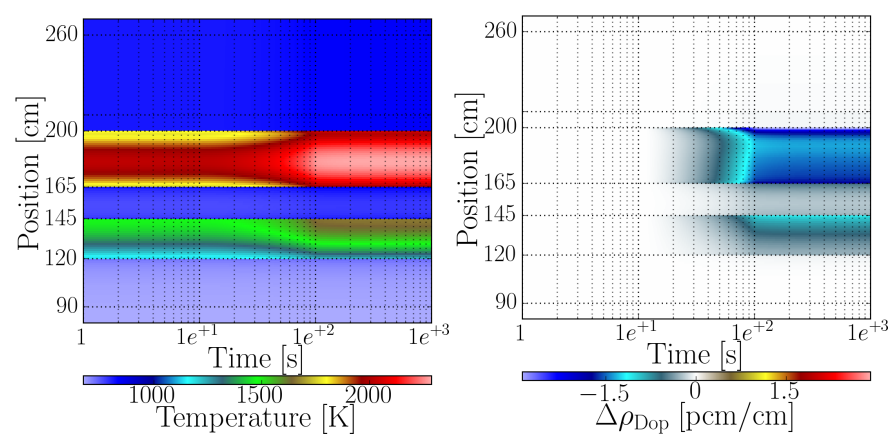

Figure 27: Fuel temperature evolution map (left) and impact on the reactivity (right)

Due to the reactivity insertion starting at $10 \mathrm{~s}$, the first impact on the system is an increase of the power that 

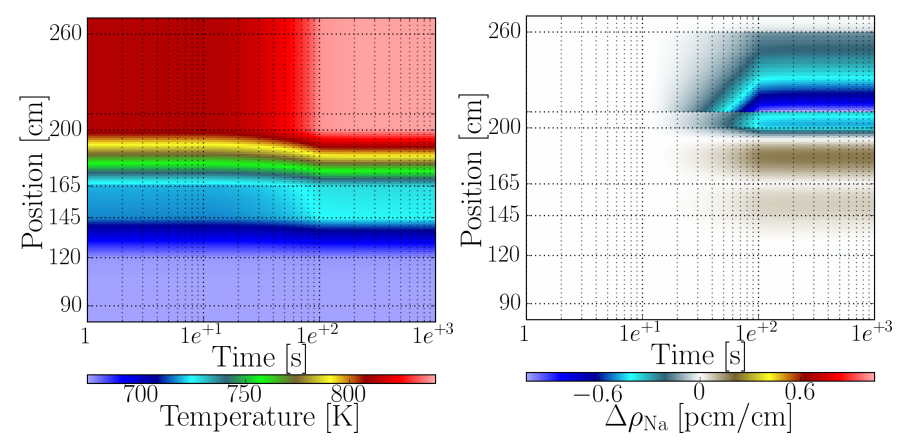

Figure 28: Sodium temperature evolution map (left) and impact on the reactivity (right)

impacts the temperatures. The Doppler and sodium density thermal feedbacks, represented on the right column of Figs. 27 and 28, provide a negative feedback compensating the reactivity insertion. Compared to the ULOF calculation of section 4, we can see here that the two components are negative since the fuel temperature increases.

At $100 \mathrm{~s}$, the power stabilises at a maximum level, the thermal feedbacks compensating exactly the $100 \mathrm{pcm}$ inserted. The power redistribution is limited to $0.5 \%$ due to the small sodium temperature increase compared to the ULOF case, the redistribution being largely linked to the neutron absorptions in the $\mathrm{B}_{4} \mathrm{C}$.

\subsection{Influence of the neutronics model}

The calculation has been performed using both CEA/IAEC and SK/PK tools and models. Figures 15, 16 and 17 present the results of each case for the temperature, the reactivity and the power variation.

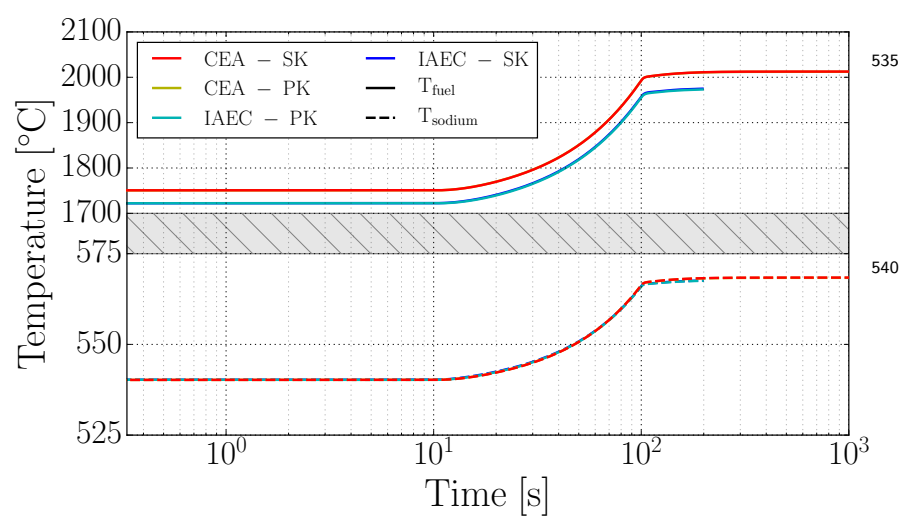

Figure 29: Evolution of the fuel and sodium maximum temperatures ${ }^{545}$ - UTOP

A similar behaviour between each code and method is obtained on each parameter. The results between the SK and the PK are very close, and a small difference exists550 between the CEA and IAEC results. The slight difference on the fuel maximum temperature is due to the power shape that is slightly different and impacts this maximum value. However, it does not impact the relative power stabilisation that is around $120 \%$ in both case.

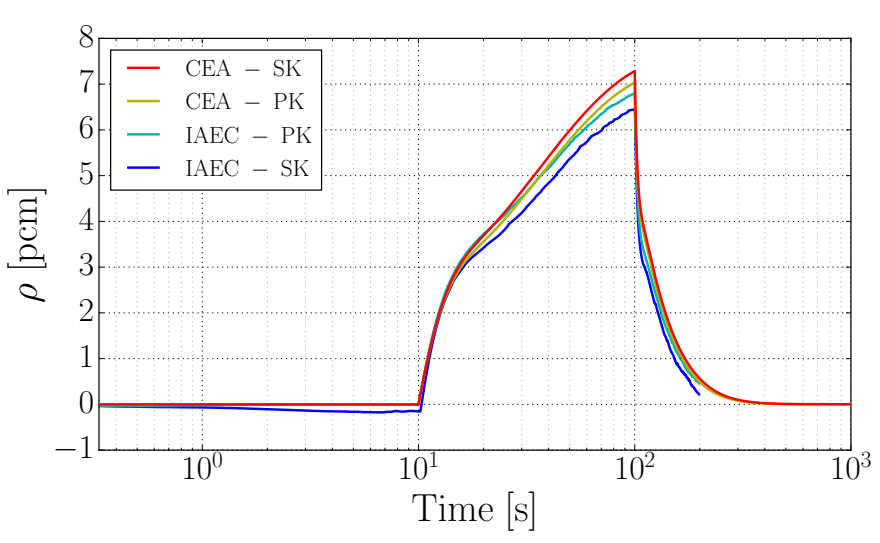

Figure 30: Reactivity evolution - UTOP

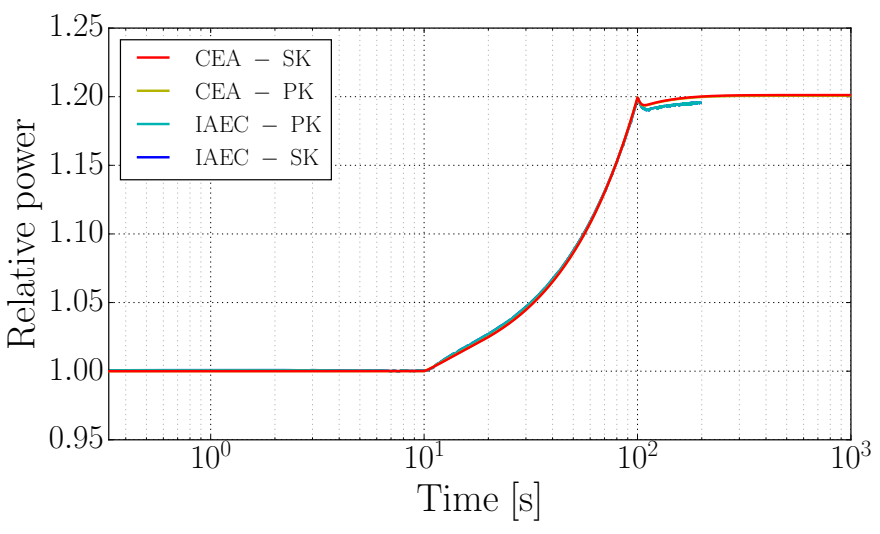

Figure 31: Relative power evolution - UTOP

A small difference also appears on the reactivity before the beginning of the transient (10 s) due to the slow SK stabilization of the system, even if this reactivity variation is limited to $0.2 \mathrm{pcm}$ and is negligible. We can see that the maximum value reached during the transient is only around $7 \mathrm{pcm}$ at $100 \mathrm{~s}$ for $100 \mathrm{pcm}$ inserted thanks to the feedbacks, and the exact value depends on the feedback coefficients of each approach.

\section{Conclusion}

This article presents the impact of the neutron modeling on a representative ASTRID assembly for ULOF and UTOP calculations. Different neutronics models are tested. The first neutronic model considered, the TFM approach, is based on a Monte Carlo precalculation of the system response associated to an interpolation model, and the second one is a deterministic discrete ordinate $\mathrm{S}_{\mathrm{N}}$ approach solving the neutron equation in time, position, energy, and angle. These two approaches are used to perform both spatial and point kinetics calculations through the generation of local feedback coefficients.

In order to check the agreement of the thermalhydraulics and coupling tools, the ULOF transient has been calculated using the same point kinetics parameters with 
the two calculation codes and a very good agreement is obtained. The axial power shape redistribution during the considered transient is limited to $+2 /-4 \%$ for the $\mathrm{ULOF}^{615}$ calculation, the sodium density decrease at the top of the reactor inducing a power shift in the lower fissile area. The global system evolution is very similar for each code between its spatial kinetic and its point kinetics resolutions. ${ }^{620}$ The difference on the reactivity variation is limited to a few pcm. The main discrepancy observed concerns the neutronics TFM and $\mathrm{S}_{\mathrm{N}}$ approaches used. The difference on the reactivity is limited to around $10 \mathrm{pcm}$ for the $\mathrm{ULOF}^{625}$ and 1 pcm for the UTOP and, and due to the discrepancy of the global feedback coefficients, the difference between the final power stabilization levels is of around $5 \%$ for the ULOF case.

The benchmark highlights that the neutronics modeling approach $\left(\mathrm{S}_{\mathrm{N}}\right.$ vs TFM) has a larger impact on the transient evolution than the spatial kinetics compared to the point kinetics even the power redistribution provides a useful information. Complementary studies will be required on other scenarios that may induce a spatial decoupling with a larger perturbation amplitude such as sodium boiling or full core calculations with radially non uniform perturbations.

\section{Acknowledgments}

The authors wish to thank the IN2P3 department of the CNRS (National Center for Scientific Research) for its support during the initial development of the TFM approach, the IAEC (Israel Atomic Energy Commission) for its support during this research and to Dr. Erez Gilad for his contribution to the code development on the IAEC side.

\section{References}

[1] B. Fontaine, et al., Sodium-cooled fast reactors: the ASTRID plant project, in: Proc. GLOBAL, 2011, pp. 11-16.

[2] P. Sciora, D. Blanchet, L. Buiron, B. Fontaine, M. Vanier, F. Varaine, C. Venard, S. Massara, A.-C. Scholer, D. Verrier, Low void effect core design applied on 2400 MWth SFR reactor, in: International Congress on Advances in Nuclear Power Plants (ICAPP), 2011.

[3] A. Koning, R. Forrest, M. Kellett, R. Mills, H. Henriksson, Y. Rugama, et al., The JEFF-3.1 nuclear data library, OECD, 2006.

[4] M. Inoue, K. Maeda, K. Katsuyama, K. Tanaka, K. Mondo, M. Hisada, Fuel-to-cladding gap evolution and its impact on thermal performance of high burnup fast reactor type uraniumplutonium oxide fuel pins, Journal of nuclear materials 326 (1) (2004) 59-73.

[5] J. J. Carbajo, G. L. Yoder, S. G. Popov, V. K. Ivanov, A review of the thermophysical properties of $\mathrm{MOX}$ and $\mathrm{UO}_{2}$ fuels, Journal of Nuclear Materials 299 (3) (2001) 181-198.

[6] G. Rimpault, D. Plisson, J. Tommasi, R. Jacqmin, J. Rieunier, D. Verrier, D. Biron, The ERANOS code and data system for fast reactor neutronic analyses, in: Proc. Int. Conf. PHYSOR, Vol. 2, 2002, pp. 7-10.

[7] E. E. Lewis, W. F. Miller, Computational methods of neutron transport.
[8] S. Dulla, E. H. Mund, P. Ravetto, Accuracy of a predictorcorrector quasi-static method for space-time reactor dynamics, PHYSOR.

[9] S. Dulla, E. H. Mund, P. Ravetto, The quasi-static method revisited, Progress in Nuclear Energy 50 (8) (2008) 908-920.

[10] H. Jasak, A. Jemcov, Z. Tukovic, et al., OpenFOAM: A C++ library for complex physics simulations, in: International workshop on coupled methods in numerical dynamics, Vol. 1000, IUC Dubrovnik, Croatia, 2007, pp. 1-20.

11] A. Laureau, Développement de modèles neutroniques pour le couplage thermohydraulique du MSFR et le calcul de paramètres cinétiques effectifs, Ph.D. thesis, Université Grenoble Alpes (2015).

[12] A. Laureau, M. Aufiero, P. Rubiolo, E. Merle-Lucotte, D. Heuer, Coupled neutronics and thermal-hydraulics transient calculations based on a fission matrix approach: application to the Molten Salt Fast Reactor, in: Joint International Conference on Mathematics and Computation, Supercomputing in Nuclear Applications and the Monte Carlo Method (M\&C+ SNA+ MC 2015), Nashville, USA.

[13] A. Laureau, M. Aufiero, P. Rubiolo, E. Merle-Lucotte, D. Heuer, Transient Fission Matrix: Kinetic calculation and kinetic parameters $\beta_{\text {eff }}$ and $\Lambda_{\text {eff }}$ calculation, Annals of Nuclear Energy 85 (2015) 1035-1044.

[14] W. Bernnat, A Monte Carlo Technique for Local Perturbations in Multiplying Systems, in: Proc. NEACRP Specialist Meeting, ANL-75-2, 1974, p. 261.

[15] J. Leppänen, M. Pusa, T. Viitanen, V. Valtavirta, T. Kaltiaisenaho, The Serpent Monte Carlo code: Status, development and applications in 2013, Annals of Nuclear Energy 82 (2015) $142-150$ 